\title{
PENGARUH LUMPUR PEMBORAN DENGAN EMULSI MINYAK TERHADAP KERUSAKAN FORMASI BATU PASIR LEMPUNGAN (ANALISA UJI LABORATPORIUM)
}

\author{
INFLUENCE MUD DRILLING WITH EMULSION OIL \\ TO FORMATION DAMAGE of CLAY LIMESTONE \\ (TESTING LABORATORY ANALYSIS)
}

\author{
FITRIANTI \\ Jurusan Teknik Perminyakan Fakultas Teknik Universitas Islam Riau \\ Jl. Kaharuddin Nasution 113 Pekanbaru-28284 \\ Bundakekey1@gmail.com
}

\begin{abstract}
Abstrak
Porositas dan permeabilitas merupakan bagian dari sifat fisik batuan yang memiliki keterkaitan. Porositas merupakan perbandingan dari volume bulk batuan terhadap total volume batuan sementara permeabilitas merupakan ukuran media berpori untuk meloloskan fluida agar fluida dapat mengalir. Untuk menentukan harga porositas dan permeabilitas tersebut dapat dilakukan pada uji laboratorium. Dengan adanya perbandingan harga permeabilitas dari sample batuan, dapat diketahui seberapa besar nilai skin dari batuan reservoir tersebut. Tujuan dari penelitian ini yaitu untuk mengetahui seberapa besar pengaruh lumpur pemboran dengan emulsi minyak terhadap kerusakan formasi batu pasir lempungan. Adapun data yang menjadi acuan utama untuk penelitian ini adalah data permeabilitas dari sample core yang didapat dengan menggunakan alat Gas Permeameter. Dalam penelitian ini , Sample core yang digunakan yaitu sample core batu pasir lempungan sebanyak 10 buah dengan harga porositras yang seragam sesuai dengan pengukuran helium porosimeter dan akan dikontaminasi terhadap lumpur pemboran emulsi minyak. Pembuatan lumpur emulsi minyak disesuaikan dengan standar API SPEC. Sifat fisik lumpur yang perlu diukur dalam penelitian ini yaitu : Densitas lumpur, Rheologi lumpur, pH lumpur, Filtare lumpur dan ketebalan Mud Cake. Setelah dilakukan pengukuran dan uji laboratorium didapat harga permeabilitas sample core rata - rata sebelum dijenuhi dengan lumpur pemboran sebesar 1.2 Darcy dan permeabilitas rata - rata sample core setelah dijenuhi dengan lumpur pemboran sebesar 0.13 Darcy. Dari hasil perbandingan permeabilitas awal dan permeabilitas akhir sample core didapat nilai kerusakan sample core setelah dikontaminasi dengan lumpur emulsi minyak sebesar 8.2. Dari hasil penelitian yang telah dilakukan maka dapat disimpulkan bahwa kerusakan sample core batu pasir lempungan setelah dikontaminasi dengan lumpur emulsi minyak cukup besar jika dibandingakan dengan kontaminasi pada sample core batu pasir, yang ditunjukkan oleh kecilnya harga skin dari sample core tersebut.
\end{abstract}

Kata Kunci : Sifat Fisik Batuan, Permeabilitas, Skin Factor, sample core

\begin{abstract}
Porosity and permeability are part of the physical properties of rocks that have relevance. Porosity is the ratio of bulk rock volume to total volume of rock while the permeability is a measure of a porous medium for the passage of fluid so that fluid can flow. To determine the price of porosity and permeability can be performed on laboratory testing. With the price comparison permeability of rock samples, can be known how much the skin of the reservoir rock. The purpose of this research is to find out how big the influence of drilling mud to damage the productive formation. The main reference for this study is the permeability data from core samples obtained by using Gas Permeameter. In this study there are two types of core samples and 2 types of drilling mud used. Sample cores used in this research that core samples of sandstone and sandstone core samples with the contaminants clay water-based drilling mud and drilling mud oil emulsion. After doing research, the price of
\end{abstract}


skins obtained from each core sample. For the sandstone core samples with contaminant water base mud skins mud value of 3.72, for samples of sandstone cores with oil emulsion mud contaminants skin value of 2.36 , for the sandstone core samples with the contaminants lempungan water base mud skins mud at 16.37 and the value for sample lempungan sandstone cores with oil emulsion mud contaminants skin value of 8.18. From the results of research that has been done then we can conclude that the greatest damage occurred in lempungan sandstone with mud contaminant and water base mud smallest damage on sandstone with oil emulsion sludge contaminants. This is because the clay reacts with water causing swelling clay at the core sample saturated with water-based drilling mud.

Key Words : Rock Properties, Permeability, Skin Factor, Sample core

\section{PENDAhULUAN}

Operasi pemboranan merupakan kegiatan penting yang harus dilakukan untuk mendapatkan hidrocarbon. Dalam upaya pencapaian hidrocarbon tersebut, selama operasi pemboran mata bor akan menembus beberapa macam lapisan formasi, baik formasi sand hingga formasi shally shale.

Selama proses pemboran berlangsung, lumpur pemboran akan terus disirkulasikan hingga kegiatan pemboran selesai dilakukan. Saat sirkulasi lumpur pemboran, filtrat lumpur akan masuk ke dalam pori - pori batuan dan merusak sifat fisik dari batuan tersebut, terutama harga porositas dan permeabilitas dari batuan formasi. Secara teoritis, kerusakan formasi batu pasir lempungan akan lebih besar dibandingkan dengan kerusakan formasi batu pasir, setelah disirkulasikan dengan lumpur pemboran berbahan dasar minyak, hal ini disebabkan karena pada formasi batu pasir lempungan clay dapat bereaksi dengan air sehingga menyebabkan terjadinya pengembangan clay (clay swelling) pada formasi batu pasir lempungan yang terkontaminasi oleh lumpur pemboran. Besarnya kerusakan formasi dapat dilakukan dengan membandingkan harga permeabilitas melalui uji laboratorium dengan menggunakan gas permeameter.

Penelitian ini bertujuan untuk menghitung nilai kerusakan formasi batu pasir lempungan setelah dikontaminasi dengan lumpur pemboran emulsi minyakberdasarkan uji laboratorium. Adapun parameter yang mencadi acuan utama dalam penelitian ini yaitu menentukan nilai skin melalui perbandingan antara harga permeabilitas awal dan permeabilitas akhir dari sample core yang diuji. 
Untuk pembuatan lumpur pemboran dengan emulsi minyak, disesuaikan dengan standar API SPEC. Sebelum sample core dijenuhi dengan lumpur pemboran emulsi minyak, terlebih dahulu diukur sifat fisik dari lumpur pemboran tersebut. Sifat fisik lumpur yang perlu diukur yaitu: Densitas lumpur pemboran, rheologi lumpur pemboran, $\mathrm{pH}$ lumpur pemboran, fitrat lumpur pemboran dan ketebalan mud cake.

Hasil akhir yang diperoleh dari penelitian ini adalah seberapa besar kerusakan sample core akibat kontaminasi lumpur pemboran emulsi minyak dan sekaligus mendapatkan referensi tentang pengaruh lumpur pemboran emulsi minyak terhadap kerusakan formasi batu pasir.

\section{TINJAUAN PUSTAKA}

\subsection{Formasi Produktif}

Pada umumnya berdasarkan asal-usul terbentuknya batuan, batuan formasi dibedakan menjadi batuan beku, batuan metamorf dan batuan sedimen. Dari ketiga jenis batuan formasi tersebut, batuan sedimen mempunyai peran yang sangat penting artinya dalam dunia perminyakan, karena batuan ini sebagian besar merupakan batuan reservoir. Walaupun demikian tidak jarang dalam kondisi tertentu batuan beku maupun batuan metamorf dapat pula menjadi batuan reservoir hidrokarbon. Tiga jenis batuan sedimen yang dapat bertindak sebagai batuan reservoir adalah batupasir dan batuan shale (klastik), serta batuan karbonat (non-klastik). Masing-masing batuan tersebut mempunyai sifat fisik yang berbeda, begitu pula komposisi kimianya. Karena mempunyai sifat utama porous dan permeable sebagai syarat terbentuknya reservoir juga memiliki kondisi tekanan dan temperatur yang mendukung, maka sangat potensial dari ketiga jenis batuan tersebut disebut sebagai source rock. Dan jika fluida mature (matang) reservoir mengalami migrasi kemudian akan terakumulasi dibatasi oleh cap rock dalam kondisi yang setimbang, maka fluida inilah yang menjadi proyek bagi dunia industri perminyakan.

Sifat-sifat unsur penyusun batuan reservoir perlu diketahui mengingat jenis dan jumlah unsurunsur tersebut akan menentukan sifat-sifat dari mineral yang dibentuknya, baik sifat fisik maupun sifat kimiawinya.

\section{a. Clay}

Clay sebagian besar dapat ditemukan di semua batuan reservoir. Clay mempunyai sifat dan karakter yang spesifik sehingga perlu dipelajari. Clay dapat menimbulkan pengaruh negatif 
baik dalam reservoir, operasi pemboran maupun dalam operasi produksi. Lapisan clay dapat berupa lapisan tebal atau lapisan tipis berselang - seling dengan lapisan batupasir atau lapisan karbonat. Clay tersebar dalam batupasir sebagai butiran-butiran yang mengisi celah antar butiran pasir yang bertindak sebagai semen. Clay umumnya terdapat di dalam batu pasir. Di dalam batuan karbonat clay tidak bereaksi dalam jumlah yang besar. Material yang dapat diklasifikasikan ke dalam clay adalah butiran yang mempunyai ukuran lebih kecil dari pada 5 mikron. Clay bisa mempunyai bermacam-macam komposisi kimia, reaktivitas yang berbeda terhadap pori batuan dan secara fisik mempunyai banyak susunan.

Clay mempunyai sifat plastis, dengan kata lain ia dapat mengisap air dan dapat dibentuk suatu benda yang dapat dibentuk sesuka hati (seperti lempung). Sifat plastik clay bila basah tidak akan menghidrat (inerd solid) dan akan mempengaruhi viscositas dan densitas bahkan dapat membentuk gumpalan. Clay terdiri dari mineral-mineral silika, aluminium, dengan kationkation alkali tanah seperti $\mathrm{Na}, \mathrm{K}, \mathrm{Ca}, \mathrm{Mg}$ dan $\mathrm{Ba}$. Kenampakan clay tidak berarti bahwa akan terjadi masalah selama produksi berlangsung. Clay akan menjadi masalah apabila dalam reservoir terdapat dalam jumlah yang besar dan bereaksi terhadap aliran fluida yang melalui pori - pori batuan.

\section{a. Sifat Fisik Batuan Reservoir}

Secara umum sifat fisik batuan antara lain meliputi porositas, wettabilitas, tekanan kapiler, saturasi fluida, permeabilitas, dan kompressibilitas batuan. Adapun sifat fisik batuan yang paling penting dalam penelitian ini yaitu porositas dan permeabilitas.

\section{$\underline{\text { Porositas }}$}

Porositas merupakan ukuran ruang-ruang kosong dalam suatu batuan yang mempunyai kemamapuan menyimpan hidrokarbon. Secara definitif porositas merupakan perbandingan antara volume ruang kosong yang berada dalam batuan berupa pori terhadap volume batuan secara keseluruhan, dan biasanya diekspresikan dengan stuan fraksi atau prosentase (\%). Notasi yang dipakai untuk porositas, $\phi$. Secara matematis porositas batuan dapat ditulis sebagai berikut :

$$
\text { Porositas, } \phi=\frac{V b-V s}{V b}=\frac{V p}{V b}
$$

keterangan :

$\mathrm{Vb} \quad=$ volume batuan total (bulk volume) . 
Vs = volume padatan batuan total (volume grain)

$\mathrm{Vp} \quad=$ volume ruang pori-pori batuan

\section{$\underline{\text { Permeabilitas }}$}

Permeabilitas didefinisikan sebagai kemampuan dari suatu batuan untuk mengalirkan fluida melalui pori-pori batuan tanpa merusak partikel pembentuk batuan. Permeabilitas merupakan fungsi tingkat hubungan ruang antar pori-pori dalam batuan. Definisi kuantitatif permeabilitas pertama-tama dikembangkan oleh Henry Darcy (1856) dalam hubungan empiris dengan bentuk differensial sebagai berikut:

$$
V=q / A=-\frac{k}{\mu} \cdot \frac{d P}{d L}
$$

\section{keterangan:}

$\mathrm{q} \quad=$ laju aliran, $\mathrm{cc} / \mathrm{sec}$

A = luas penampang media berpori, $\mathrm{cm}^{2}$

$\mathrm{V}=$ kecepatan aliran, $\mathrm{cm} / \mathrm{sec}$.

$\mu \quad=$ viskositas fluida yang mengalir, $\mathrm{cp}$.

$\mathrm{dP} / \mathrm{dL}=$ gradien tekanan dalam arah aliran, $\mathrm{atm} / \mathrm{cm}$.

$\mathrm{k} \quad=$ permeabilitas media berpori, darcy.

\subsection{Teori Dasar Lumpur Pemboran}

Lumpur pemboran merupakan suatu cairan yang terdiri dari campuran material dan additive yang digunakan selama operasi pemboran berlangsung. Akibat dari sirkulasi lumpur pemboran, terjadi kerusakan pada formasi yang terkontaminasi oleh lumpur pemboran

Secara umum lumpur pemboran mempunyai empat komponen dasar, yaitu 8 :

1. Komponen Cair

2. Komponen Padat Reaktif

3. Komponen Padat Innert

4. Komponen Additive/Pengontrol

\subsection{Fungsi Lumpur Pemboran}

Fungsi utama lumpur pemboran adalah :

1. Mengangkat serbuk bor ke permukaan.

2. Mengontrol tekanan formasi

3. Mendinginkan serta melumasi pahat dan drillstring 
4. Membersihkan dasar lubang bor

5. Membantu dalam evaluasi formasi

6. Melindungi formasi produktif

7. Membantu stabilitas formasi

\subsection{Sifat-Sifat Fisik Lumpur Pemboran}

Sifat fisik Lumpur yang terpenting yang dikontrol pada setiap operasi sumur migas dan panas bumi ada tiga, yaitu:

1. Densitas

2. Rheologi (sifat aliran)

3. Filtration Loss

\section{$\underline{\text { Densitas }}$}

Pengontrolan densitas lumpur pada hakekatnya adalah mencegah blow out, dan kadangkadang juga digunakan untuk menjaga stabilitas lubang bor. Lumpur yang terlalu berat dapat menyebabkan terjadinya lost sirculation, sedangkan, lumpur yang terlalu ringan dapat menyebabkan masuknya fluida formasi ke dalam lubang bor (kick) dan jika tidak segera diatasi akan menyebabkan terjadinya semburan liar (blow out).

\section{$\underline{\text { Rheologi (Sifat Aliran) }}$}

Pengontrol rheologi diperlukan untuk mengangkat serbuk bor (cutting) pada saat pemboran berlangsung. Dalam terminology lapanga minyak, istilah "sifat aliran" (flow properties) dan "viscositas" adalah merupakan ungkapan umum yang digunakan untuk menggambarkan perilaku lumpur pemboran dalam keadaan bergerak. Viscositas fluida pemboran merupakan fungsi dari beberapa faktor, yaitu :

- Viscositas fasa cair

- Volume padatan dalam lumpur

- Volume fluida yang terdispersi (emulsi)

- Jumlah partikel per satuan lumpur

- Bentuk partikel padatan

- Gaya tarik (atau gaya tolak) antara partikel-partikel padat, dan antara fasa padat dengan fasa fluida 
Viscositas menunjukkan kekentalan lumpur dalam aliran, dan gel strength menunjukkan kekentalan lumpur dalam kondisi diam pada periode waktu tertentu. Secara ilmiah, viscositas adalah suatu konstanta antara shear stress dan shear rate untuk fluida Newtonian, seperti air, tetapi tidak berlaku untuk lumpur pemboran. Untuk fluida pemboran, perbandingan antara shear stress dan shear rate berkurang dengan naiknya shear rate.

Penggunaan utama plastic viscosity yang diukur dalam centi poises, adalah untuk menunjukkan pengaruh kandungan padatan terhadap kekentalan lumpur. Plastic viscosity diperoleh dengan mengurangkan dial reading $600 \mathrm{rpm}$ dengan $300 \mathrm{rpm}$ pada viscometer. Besarnya plastic viscosity dipengaruhi oleh kandungan padatan, ukuran padatan, dan temperatur. Sukar mengatakan bahwa lumpur berat tertentu harus mempunyai viscositas tertentu juga, karena faktor ukuran padatan berpengaruh.

Yield point adalah merupakan suatu pseudometer. Yield point ditentukan secara kuantitatif dengan pengurangan pembacaan 300 rpm dengan plastic viscosity.

Gel strength adalah merupakan suatu harga yang menunjukkan kemampuan lumpur untuk menahan padatanpadatan. Faktor yang menyebabkan terbentuknya gel strength yaitu adanya gaya tarik menarik dari partikel-partikel atau plat-plat clay sewaktu tidak adanya sirkulasi lumpur. Fungsi gel strength dalam lumpur pemboran adalah menahan cutting dan pasir dalam suspensi sewaktu sirkulasi lumpur dihentikan.

\section{Filtration Loss}

Filtration loss adalah kehilangan sebagian fasa cair (filtrate) lumpur yang masuk ke dalam formasi permeable. Filtration loss yang terlalu besar berpengaruh jelek terhadap formasi maupun terhadap lumpurnya sendiri, karena dapat menyebabkan terjadinya formation damage (pengurangan permeabilitas efektif terhadap minyak/gas) dan lumpur akan kehilangan banyak cairan. Mud cake sebaiknya tipis agar tidak memperkecil lubang bor.

\subsection{Formation Damage}

Kerusakan formasi (formation damage) didefinisikan sebagai perubahan besarnya permeabilitas yang terjadi di sekitar lubang sumur. Penyebab utama timbulnya kerusakan formasi pada sumur adalah adanya kontak antara formasi dengan fluida dari luar, dimana fluida ini dapat berupa : fluida injeksi, lumpur pemboran, fluida kerja ulang, fluida untuk 
proses stimulasi (treatment fluid), atau juga fluida formasi itu sendiri jika ternyata karakteristik reservoar tesebut telah berubah. Semua sumur minyak dapat terkena formation damage, dimana tingkatnya bermacam-macam dari turunnya produksi sampai tertutupnya zona produksi sehingga sumur tidak bisa mengalir sama sekali.

\subsection{Faktor Skin}

Stimulasi dilakukan untuk memperbaiki kerusakan di sekitar lubang sumur sehingga dapat meningkatkan produktivitas sumur. Dalam hal ini sangat penting untuk mengetahui jenis kerusakan sumur yang sedang terjadi dan hal-hal yang mungkin menyebabkan kerusakan tersebut. Kerusakan dikarakterisasi dengan dua parameter utama yaitu komposisi dan lokasi. Parameter-parameter ini akan menentukan stimulasi yang akan dilakukan untuk menghilangkan kerusakan formasi tersebut.

Lokasi kerusakan penting untuk diketahui karena fluida yang diinjeksikan akan kontak dengan beberapa substrat lain seperti karat dari casing atau material

karbonat dari semen formasi. sebelum kerusakan diperbaiki. Kuantifikasi kerusakan formasi ditunjukkan dengan factor skin dan panjang daerah tersebut di representasikan dengan zona skin. Idealisasi dari konsep zona kerusakan diillustrasikan seperti:

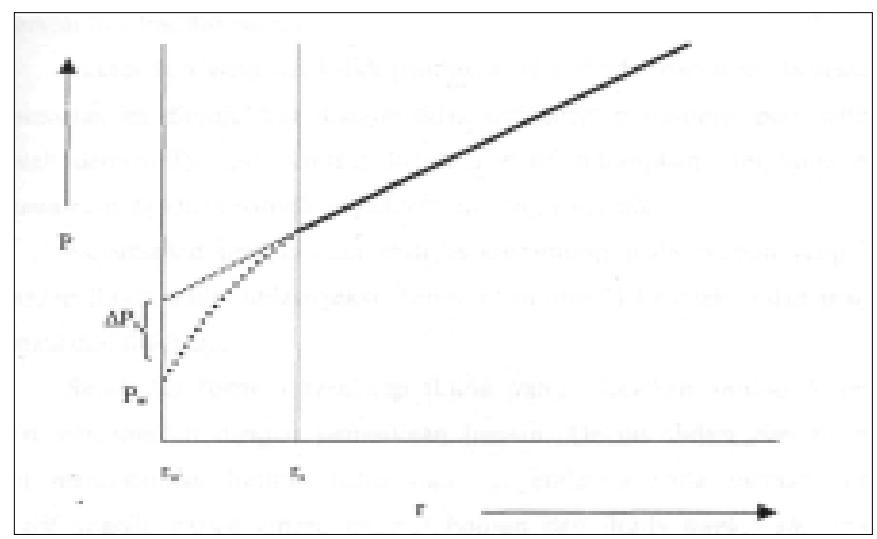

Gambar.3.16

\section{Representasi Kehilangan Tekanan Akibat Skin}

\section{PENGUJIAN LABORATORIUM}

Untuk mendapatkan nilai kerusakan sample core yang dilakukan melalui uji laboratorium, terlebih dahulu diukur harga porositas dari tiap sample core dengan menggunakan alat helium porosimeter. Sample core yang akan diuji ada 10 buah, setelah didapat 10 sample core yang seragam, diukur harga permeabilitas sample core tersebut 
dengan menggunakan gas permeameter. Selanjutnya membuat lumpur pemboran berbahan dasar air dan mengukur sifat fisik dari lumpur pemboran tersebut. Selanjutnya jenuhi sample core kedalam lumpur pemboran yang telah disiapkan selama 24 jam untuk mendapatkan nilai permeabilitas akhir dari sample core tersebut dan menghitung nilai kerusakan sample core yang diakibatkan oleh lumpur pemboran berbahan dasar air.

\subsection{Bahan - bahan yang digunakan.}

A. Bahan untuk membuat sample core

> 950 gr pasir kasar

80 gr semen

50 gr bentonite

$>$ Aquades

\section{B. Bahan untuk membuat lumpur pemboran}

$>350 \mathrm{ml}$ aquadest

$>20$ gr bentonite

$0.5 \mathrm{gr} \mathrm{CMC}$

$>10.5$ gr Diesel Oil

\subsection{Parameter yang diukur}

- Porositas sample core

- Permeabilitas sample core

- Densitas lumpur pemboran

- Rheologi lumpur pemboran

- $\mathrm{pH}$ lumpur pemboran

- Filtat lumpur dan ketebalan mud cake

\subsection{Peralatan yang digunakan}

$>$ Helium Porosimeter

$>$ Gas Permeameter

$>$ Jangka Sorong

$>$ Mud Mixer

$>$ Mud Balance

$>$ Fann VG Meter 
$>\mathrm{pH}$ Meter

$>$ Standar Filter Press

\section{PEMBAHASAN}

Pengujian sample core ini dilakukan dengan cara mengukur nilai porositas awal yang bertujuan untuk menentukan keseragaman sample core kemudian dilanjutkan dengan menghitung nilai permeabilitas awal yang nantinya dibandingkan dengan permeabilitas akhir untuk mendapatkan nilai skin dan mengetahui seberapa besar pengaruh lumpu pemboran terhadap kerusakan fomasi poduktif. Adapun maksud dari permeabilitas akhir disini adalah permeabilitas setelah dijenuhi dengan lumpur pemboran berbahan dasar air dan nilai permeabilitas setelah dijenuhi dengan lumpur pemboran dengan emulsi minyak

Untuk sample core nya sendiri, didapat dengan cara manual dengan waktu pengeringan sample core selama kurang lebih 2 (dua) hari dengan pengeringan suhu ruangan.

Adapun jenis sample core yang digunakan adalah sample core batu pasir dan jenis lumpur yang digunakan untuk menjenuhi sample core tersebut yaitu lumpur pemboran berbahan dengan emulsi minyak, dimana dalam pembuatan lumpur permboran ini disesuaikan dengan standar API. Sample core yang digunakan ada 10 buah sample core dengan harga porositas yang seragam.

Pengujian ini bertujuan untuk mengetahui seberapa besar pengaruh lumpur pemboran dengan emulsi minyak terhadap kerusakan formasi produktif. Untuk mengetahui seberapa besar kerusakan formasi yang terjadi, terlebih dahulu diukur nilai porositas awal untuk mencari keseragaman sample core dan permeabilitas awal sebagai perbandingan dengan permeabilitas akhir untuk mendapatkan nilai skin dari sample core. Setelah diukur porositas awal dan permeabilitas awal. Adapun data pengukuran porositas dan permeabilitas rata - rata yang didapat yaitu: harga porositas rata - rata sebesar $10.78 \%$ dan harga permeabilitas awal rata - rata sebesar 1.2Darcy.

Setelah diukur didapat harga porositas dan permeabilitas awal dari sample core, kemudian diukur harga permeabilitas sample core setelah dijenuhi dengan lumpur pemboran untuk mendapatkan nilai skin dari perbandingan harga permeabilitas sample cote tersebut. Adapun hasil pengukuran dari permeabilitas akhir dan Skin dari sample core batu pasir yaitu: harga Permeabilitas akhir rata - rata sebesar 0.13 Darcy dan Skin rata - rata sebesar 8.2. Untuk pengukuran porositas, sebelum sample core diukur, terlebih dahulu diukur diameter dan Panjang dari sample core serta Diameter dan Panjang dari Steel Out Plug. Maksud dari Steel Out Plug disini adalah Steel yang dikeluarkan dari tabung sebagai ganti dari sample core yang akan diuji. Adapun output yang didapat dari alat Helium Porosimeter adalah Pclose dan 
Popen dari Steel dan sample core. Untuk mendapatkan nilai porositas, selanjutnya dilakukan perhitungan yang sesuai dengan rumus yang telah ditetapkan oleh Fann.

Untuk pengukuran permeabilitas sample core, sebelum sample diukur juga perlu ditentukan Diameter dan Panjang dari sample yang akan diuji, setelah diukur kemudian sample dapat dimasukkan kedalamalat untuk diuji. Adapun outpun yang didapat dari alat Gas Permeameter yaitu Qhigh (cc/menit), Qlow(cc/menit), Phigh(cc/menit), Plow (cc/menit). Untuk mendapatkan nilai permeabilitas dari sample, terlebih dahulu konversi nilai Qhigh dan Qlow kedalam cc/detik serta nilai Phigh dan Plow kedalam atm, ini bertujuan untuk mendapatkan nilai permeabilitas dalam satuan Darcy. Setelah dikonversi dapat dilanjutkan dengan perhitungan nilai permeabilitas secara manual yang sesuai dengan procedure yang telah ditetapkan oleh Fann.

Selanjutnya dibuat lumpur pemboran berbahan dasar air yang sesuai dengan standar American Petroleum Institute SPEC, dimana pembuatan lumpur ini bertujuan untuk melakukan kontaminasi terhadap sample core. Adapun waktu penjenuhan sampe core dilakukan selama 24 jam.

Dari hasil penelitian yang telah dilakukan maka dapat disimpulkan bahwa kerusakan sample core setelah dikontaminasi dengan lumpur emulsi minyak bernilai kecil yang ditunjukkan oleh kecilnya harga skin dari sample core tersebut. Jika harga sikn kecil dari 10, kerusakan formasi bernilai kecil.

Hasil penelitian yang dilakukan sesuai dengan teori yang menyatakan semakin besar harga permeabilitas batuan, semakin besar pula nilai porositas batuan tersebut dan kerusakan formasi batu pasir lempungan dengan dijenuhi pada lumpur emulsi minyak bernilai kecil karena minyak tidak bereaksi dengan clay yang ada pada material lumpur pemboran.

\section{KESIMPULAN}

Setelah dilakukan penelitian dengan menggunakan alat Helium Porosimeter dan Gas Permeameter dapat disimpulkan bahwa :

1. Pengukuran porositas awal pada setiap sample core bertujuan untuk mencari keseragaman dari sample core dengan harga porositas rata - rata sebesar $10.78 \%$ dan harga permeabilitas awal rata - rata sebesar 1.2 dan permeabilitas akhir rata- rata sebesar 0.13

2. Kerusakan sample core batu pasir lempungan setelah dikontaminasi dengan lumpur pemboran emulsi minyak cukup besar yang ditunjukkan dengan nilai skin dari sample core setelah dijenuhi dengan lumpur emulsi minyak sebesar 8.2. 
3. Kerusakan sample core batu basir lempungan dengan kontaminan lumpur emulsi minyak lebih besar dibandingkan penjenuhan pada sample core batu pasir, hali ini disebabkan karena sample core pasir lempungan dapat bereaksi dengan air sehingga menyebabkan terjadinya pengembangan (clay swelling) pada sample core selama dijenuhi dengan lumpur pemboran.

4. Semakin besar perbandingan harga permeabilitas sample core sebelum dijenuhi dengan lumpur pemboran terhadap harga permeabilitas sample core setelah dijenuhi dengan lumpur pemboran, mengakibatkan besarnya nilai skin dari sample core tersebut.

5. Untuk sifat fisik lumpur pemboran dengan emulsi minyak harga masing - masing sifat lumpur pemboran didapat (Plastic Viscosity $3.5 \mathrm{cp}$, Density $8.51 \mathrm{ppg}$, Yield point 10.5 lb/100 ft, Gel strength 0.95 lb/100ft ${ }^{2}$, pH 7.59, Filtrat lumpur $8.5 \mathrm{ml} / \mathrm{menit}$ dan mud cake $0.5 \mathrm{~mm})$.

\section{DAFTAR SIMBOL}

\begin{tabular}{lll}
$\mathrm{A}$ & $:$ & Luas penampang \\
$\mathrm{CMC}$ & $:$ & Carboxy Methyl Cellulosa \\
$\mathrm{FD}$ & $:$ & Formation Damage \\
$\mathrm{GS}$ & $:$ & Gel Strength \\
$\mathrm{h}$ & $:$ & Kedalaman lubang bor $(\mathrm{ft})$ \\
$\mathrm{K}$ & $:$ & Permeabilitas \\
$\mathrm{K}_{\mathrm{i}}$ & $:$ & Permeabilitas sampel core sebelum dijenuhi oleh lumpur pemboran \\
$\mathrm{K}_{\mathrm{d}}$ & $:$ & Permeabilitas sampel core sesudah dijenuhi oleh lumpur pemboran \\
$\mathrm{L}$ & $:$ & Panjang sampel core \\
$\mathrm{PV}$ & $:$ & Plastic Viscosity \\
$\mathrm{Q}$ & $:$ & Laju Alir fluida (Stb /day) \\
$r_{e}$ & $:$ & Jari - jari pengurasan (ft) \\
$r_{w}$ & $:$ & Jari - jari lubang sumur (ft) \\
$\mathrm{S}$ & $:$ & Skin \\
$\mathrm{Vb}$ & $:$ & Volume batuan total (bulk volume) \\
$\mathrm{V}$ & $:$ & Volume butiran total (volume grain) \\
$\mathrm{Vp}$ & $:$ & Volume ruang pori-pori batuan \\
$\mathrm{YP}$ & $:$ & Yield Point (lb/100 sqft) \\
$\Phi$ & $:$ & Porositas, fraksi \\
$\mu$ & $:$ & Viskositas, centipoise \\
\hline & &
\end{tabular}




$\begin{array}{lll}\boldsymbol{\rho} & : & \text { Densitas } \\ \rho_{\mathrm{b}} & : & \text { Densitas bulk } \\ \boldsymbol{\rho}_{\mathrm{m}} & : & \text { Densitas lumpur } \\ \Delta \mathrm{P} & : & \text { Perubahan tekanan, Psi } \\ \Delta \mathrm{K} & : & \text { Penurunan permeabilitas }\end{array}$

\section{DAFTAR PUSTAKA}

:2002. Drilling Fluid Manual. BP \& Chevron Texaco.

Irawan, Sonny. 2001. "Mekanika Reservoir", Diktat kuliah Jurusan Teknik Perminyakan Universitas Islam Riau.

Fjelde, Ingebret. 2009. Formation Damaged Caused by Emulsions During Drilling With Emulsified Drilling Fluid. SPE Drilling \& Completion.

Kelessidis, V.C., Marinakis, D. 2007. Laboratory Assessment of Drilling Fluid Formation Damage in Sandstone Cores and Mitigation with Lignite Additives for High Temperature Fields. Netherlands.

McCain, William D. Jr. 1990. The Properties of Petroleum Fluids. PennWell Plubising Company. Tulsa. Oklahoma.

Mohammad, Alkhatha'ami. 2005. "Permeability, Porosity \& Skin factor”. Riyadh

Savari, Sharath., Kumar, Arunesh., and Jamison, Dale. Improved Lost Circulation Treatment Design and Testing Techniques Minimize Formation Damage. Netherlands, 2011.

Eirik, Norsk., Gunnar Fimreite, Andrew Dzialowski and Grete S. Svanes, Design Of Water Based Drilling Fluid System For Deep Water Norway, Amsterdam, The Netherlands, 2001

Roger, Walter F., Composition and Properties of Oil Well Drilling Fluids, Gulf Publishing Company, Houston, Texas, 1963. 